\section{How Application Times of 2,4-DP Influence the Ripening Capacity of 'La France' Pears}

\author{
Satoru Kondo ${ }^{1}$, Kazuhiro Settsu, and Anan Jitratham \\ Graduate School of Applied Biosciences, Hiroshima Prefectural University, \\ Shobara, Hiroshima 727-0023, Japan
}

Additional index words. auxin, cell wall components, ethylene, Pyrus communis, temperature

\begin{abstract}
The effective applications of synthetic auxin 2,4-DPon fruit ripening of ' $L a$ France' pears (Pyrus communis L.) were examined. A solution of $90 \mu \mathrm{L} \cdot \mathrm{L}^{-1} 2,4-\mathrm{DP}$ was applied to fruit and leaves around the fruit as follows: Early $1=140$ days after full bloom (DAFB); Early $2=140$ and 150 DAFB; Late $1=150$ DAFB; and Late $2=150$ and 160 DAFB. The effects were compared with nontreated fruit. Internal ethylene concentrations increased earliest and rapidly in Early 2 followed by Early 1 . Fruit firmness decreased earliest in Early 2 and Early 1. Water-soluble polyuronide (WSP) concentrations in Early 2 were higher than other treatments, but hexametaphosphate-soluble polyuronide (HMP) and cellulose concentrations were lower. At 200 DAFB, $40 \%$ of fruit in Early 2 reached edible condition on the tree. In addition, the fruit in Early 2 required shorter periods of time to reach edible condition in a controlled room at $20^{\circ} \mathrm{C}$ after harvest of $170,180,190$, and 200 DAFB. These results show that two 2,4-DP applications at 140 and 150 DAFB may be effective in inducing the ripening capacity of 'La France' pears on the tree. Chemical name used: 2-(2,4-dichlorophenoxy)-propionic acid (2,4-DP).
\end{abstract}

Pears (Pyrus communis L.) generally fail to ripen on the tree. This is because cell wall synthesis is believed to continue on the tree, and cell wall decomposition in fruit may be retarded while on the tree (Murayama et al., 1998). The buttery texture in pears is associated with cell wall degradation which is further promoted by ethylene (Gerasopoulos and Richardson, 1997; Murayama et al., 2002).

The ripening of 'La France' pears is stimulated by the relatively high temperature of $\approx 20$ ${ }^{\circ} \mathrm{C}$ after being stored at a low temperature of $\approx 5{ }^{\circ} \mathrm{C}$ for $10 \mathrm{~d}$. This is due to the stress of a low temperature which increases ethylene production in fruit (Blankenship and Richardson, 1985). However, our previous report showed that the ripening behaviors such as the degradation of cell walls in ' La France' pears were induced on the tree by synthetic auxin 2-(2,4-dichlorophenoxy)-propionic acid (2,4-DP) application at $90 \mu \mathrm{L} \cdot \mathrm{L}^{-1}$ (Kondo and Takano, 2000). 2,4-DP is used in Japan on apples [Malus sylvestris (L.) Mill. var. domestica (Borkh.) Mansf.] as a chemical which reduces preharvest fruit drop (Kondo and Hayata, 1995). Apple cultivars that have preharvest fruit drop receive a $45 \mu \mathrm{L} \cdot \mathrm{L}^{-1} 2,4-\mathrm{DP}$ solution application 15 or $25 \mathrm{~d}$ before harvest. Ethylene production was induced when 2,4-DP was applied to 'La France' pear fruit on the tree (Kondo and Takano, 2000). However, differences in ethylene production were observed among each fruit as well as the uneven ripening caused by these differences.

Received for publication 23 July 2003. Accepted for publication 12 Aug. 2003.

${ }^{1}$ To whom reprint requests should be addressed E-mail address: s-kondo@bio.hiroshima-pu.ac.jp
In this study, the effects of application dates and frequencies of 2,4-DP solution on the ripening capacity of pears were examined.

\section{Materials and Methods}

Twenty-five 13- to 14-year-old 'La France' pear trees grafted onto 'Quince C' (Cydonia oblonga Mill.) rootstock were randomly selected from an open field at Hiroshima Prefectural Univ. in 2001 and 2002. The average of the results from both years are reported. Each tree was trained as central leader and planted in a single row from east to west with spacing of $3.0 \mathrm{~m} \times 4.0 \mathrm{~m}$. The test groups were randomly allocated to individual trees which had also been chosen randomly. Five test groups of five trees each were created as follows: 1) Nontreated (nontreated with 2,4DP); 2) Early 1 [treated with 2,4-DP at $140 \mathrm{~d}$ after full bloom (DAFB)]; 3) Early 2 (treated with 2,4-DP at 140 and 150 DAFB); 4) Late 1(treated with 2,4-DP at 150 DAFB); and 5) Late 2 (treated with 2,4-DP at 150 and 160 DAFB). Fifteen fruit from each group of five trees (three fruit per tree) were labeled and measured for diameter every $7 \mathrm{~d}$ between 139 to 188 DAFB. A sufficient volume of 2,4-DP at $90 \mu \mathrm{L} \cdot \mathrm{L}^{-1}$ was applied to fruit and leaves around the fruit. Samples of 40 fruit (eight from each tree) were then taken between 170 to 207 DAFB at 7-10 d intervals. After the fruit were taken from the tree, half of them (20 fruit) were analyzed for firmness, internal ethylene concentration (IEC), and cell wall component. The other group of 20 fruit was immediately stored in a controlled room of $20^{\circ} \mathrm{C}$ and $90 \%$ relative humidity $(\mathrm{RH})$, then inspected every $2 \mathrm{~d}$ for edibility (firmness $\leq 0.3 \mathrm{~N} / \mathrm{mm}$ ).

Fruit firmness, hue value, internal ethyl- ene concentration. Ten fruit from each sample group were chosen and analyzed for color using a chromameter (CR-200; Minolta, Osaka, Japan). Hue values on the fruit surface were determined as in the previous report (Kondo and Takano, 2000). Fruit firmness was determined with a rheometer (NRM-2002J; Fudo, Tokyo; needle diameter $=1 \mathrm{~mm}$ ) at the fruit's equator after the skin had been removed with a knife after fruit color was measured. IEC was measured immediately after sampling. Ethylene concentration was measured in five fruit (subsample of the previous 10 fruit) from each sample group by withdrawing a 1-mL air sample from the fruit's core with a syringe and injecting it into a gas chromatograph (GC-380; GL Sciences, Tokyo; $\operatorname{column}=$ Porapak Q, i.d. $2.2 \mathrm{~mm} \times 2.0 \mathrm{~m}$ ).

Cell wall extraction and analysis. Ten fruit from each sample group (three replications of three separate groups consisting of three fruit, three fruit, and four fruit) were used for polyuronide analysis. After the pulp tissue was heated in $13.7 \mathrm{~mol} \cdot \mathrm{L}^{-1}$ ethanol at $70{ }^{\circ} \mathrm{C}$ for 30 $\mathrm{min}$, it was homogenated in ethanol adjusted to maintain $13.7 \mathrm{~mol} \cdot \mathrm{L}^{-1}$. After the homogenate was passed through a glass filter, the residue was washed repeatedly with $13.7 \mathrm{~mol} \cdot \mathrm{L}^{-1}$ ethanol until sugars could not be detected, followed by $17.1 \mathrm{~mol} \cdot \mathrm{L}^{-1}(100 \%)$ ethanol, $13.6 \mathrm{~mol} \cdot \mathrm{L}^{-1}(100 \%)$ acetone and $9.6 \mathrm{~mol} \cdot \mathrm{L}^{-1}$ (100\%) diethyl ether to obtain the alcohol-insoluble solids (AIS). After diethyl ether was removed, AIS was dried at below $40{ }^{\circ} \mathrm{C}$ in a vacuum oven and placed in a desiccator over phosphorus pentoxide for at least $24 \mathrm{~h}$ and then powdered. AIS of $100 \mathrm{mg}$ was suspended in $50 \mathrm{~mL}$ of distilled water, shaken overnight and filtered.

From the filtrate, water-soluble polyuronide (WSP) concentration was determined. The residue was resuspended at $90^{\circ} \mathrm{C}$ for $1 \mathrm{~h}$ in a $50-\mathrm{mL}$ solution of $0.4 \%$ sodium hexametaphosphate. After filtration, the filtrate was used to determine the hexametaphosphate-soluble polyuronide (HMP) concentration. In each fraction, the polyuronide concentration was expressed as the galacturonic acid concentration using the 3,5-dimethyl phenol method (Manabe, 1993). For hemicellulose (HCE) analysis, the residue was washed with distilled water, suspended in 0.89 м potassium hydroxide $10 \mathrm{~mL}$ for $24 \mathrm{~h}$. Following filtration, the filtrate was adjusted to $\mathrm{pH} 7$ by the addition of $6 \mathrm{~m}$ hydrochloric acid. The HCE concentration was estimated by the phenol-sulfuric acid method (Mizuno and Iwata, 1964). The residue was washed with distilled water, dried, and the remaining cellulose (CE) was weighed.

The least significant difference (LSD) procedure and analysis of variance (ANOVA) were performed using the Statistical Analysis System (SAS Inst., Cary, N.C.). Means in the figures were compared using LSD, $P \leq 0.05$.

\section{Results}

IEC increased earliest in Early 2 after 180 DAFB, followed by Early 1 and then Late 2 (Fig. 1). IEC increased significantly after 200 DAFB in Late 1. Although IEC also increased 


\section{Growth Regulators}

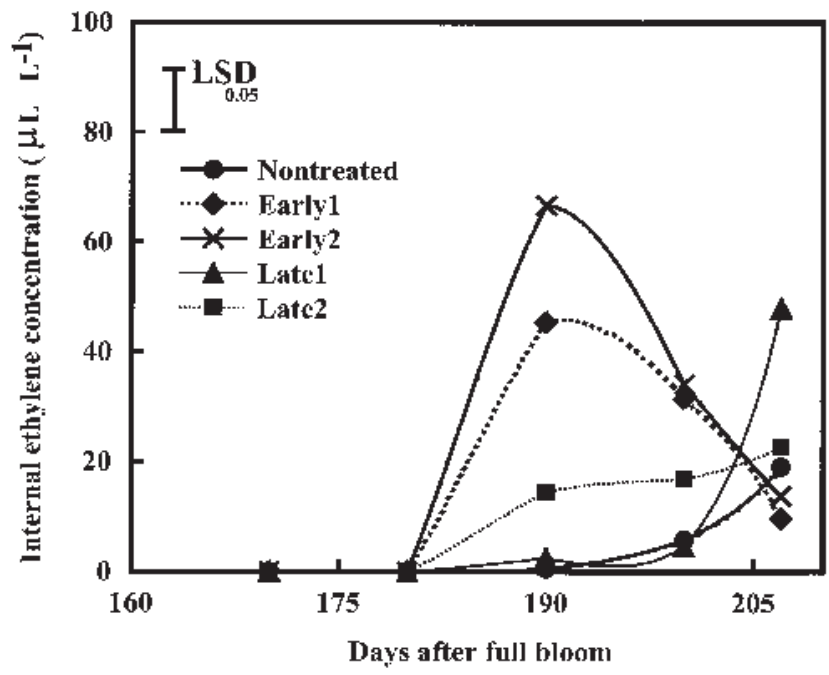

Fig. 1. Internal ethylene concentrations of pears on the tree. Nontreated (nontreated with 2,4-DP), Early 1 [treated with 2,4-DP at $140 \mathrm{~d}$ after full bloom (DAFB)], Early 2 (treated with 2,4-DP at 140 and 150 DAFB), Late 1 (treated with 2,4-DP at 150 DAFB), Late 2 (treated with 2,4-DP at 150 and 160 DAFB). Data are the means of 5 fruit. The $90 \mu \mathrm{L} \cdot \mathrm{L}^{-1} 2,4-\mathrm{DP}$ solution was applied to fruit and leaves around the fruit.

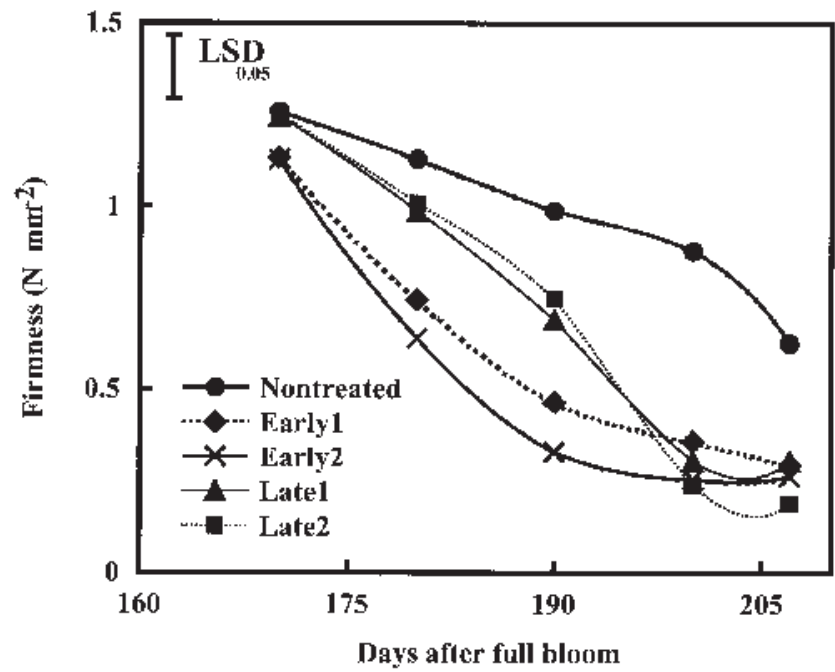

Fig. 2. Fruit firmness of pears on the tree. Data are the means of 10 fruit. in Nontreated after 190 DAFB, the rates of increase were low. Fruit firmness decreased earliest in Early 2 and Early 1 (Fig. 2). In contrast, the decrease in fruit firmness was delayed in Nontreated. In each treatment, WSP increased with DAFB, but HMP, HCE, and $\mathrm{CE}$ concentrations decreased (Table 1). At each measurement, WSP concentrations were always the highest in Early 2, and the lowest in Nontreated. In contrast, HMP, HCE, and $\mathrm{CE}$ concentrations in Nontreated were the highest each time.

Fruit with later harvests and fruit in Early 2 required less time to reach edible condition after harvest, than fruit which was not treated with 2,4-DP (Fig. 3). At 200 DAFB, $40 \%$ of the fruit in Early 2 reached edible condition on the tree. In the fruit treated with 2,4-DP, skin color became yellow with DAFB, but the skin of nontreated-fruit remained green (Fig. 4). From 153 to 188 DAFB, fruit growth in Early 1 and Early 2 decreased compared to Nontreated (Fig. 5).

\section{Discussion}

Auxin stimulates ethylene production by inducing ACC synthase (Peck and Kende, 1995). In general, the rate of ethylene production rises in a linear slope as the temperature increases until $30{ }^{\circ} \mathrm{C}$ (Saltveit, 1992). Therefore, the ripening process of 'La France' pears on the tree may be influenced by ambient temperature after 2,4-DP application. Environment factors such as drought and excessive water also influence ethylene production. These factors promote stress ethylene production in many plants (Saltveit, 1992). In our study, measurements were taken in two successive years. The average temperature and precipitation per day, for $10 \mathrm{~d}$ before and after 2,4-DP application, was $24.2^{\circ} \mathrm{C}$ and $3.7 \mathrm{~mm}$, respectively. However, two applications of 2,4-DP at 140 and 150 DAFB significantly increased ethylene production in fruit (Fig. 1). Ethylene induces cell wall degradation (Ferguson, 1984). The degradation of cell wall components such as polyuronide, $\mathrm{HCE}$, and $\mathrm{CE}$ are associated with softening in many kinds of fruit (Abu-sarra and Abu-goukh, 1992; McCollum et al., 1989). Although the process of cell wall degradation varies among fruits, the WSP fraction increased in ripening pears (Yoshioka et al., 1992). In addition, it has been shown that WSP concentrations are associated with texture and firmness in pears (Murayama et al., 2002). In our study, the increase of WSP and the decrease of HMP and $\mathrm{CE}$ were observed in fruit in which ethylene concentrations rose sharply. Therefore, the ripening capacity of 'La France' pears on the tree may be enhanced by a sharp rise rather than a gentle rise. That is, the $90 \mu \mathrm{L} \cdot \mathrm{L}^{-1}$ 2,4-DP applications of two times may enhance ripening capacity. However, the application of 2-chloroethyl phosphonic acid (ethephon), which generates ethylene, induced fruit ab- scission dramatically (Kondo, unpublished data). This inconsistency can be understood after explanation. The ethylene production by 2,4-DP does not induce fruit abscission because auxin inhibits the formation of the abscission layer (Kondo and Hayata, 1995).

Our previous report showed that the ripening stage could be evaluated by the changes in skin color from green to yellow (Kondo and Takano, 2000) and Early 2 advanced these changes. The changes in skin color were not observed in 'La France' pears, which ripened at room temperature after cold storage (Kondo and Takano, 2000). Therefore, sharp ethylene production may promote degreening of pear fruit as well as apples (Lau et al., 1986). Although we showed previously that the ripening period at $20{ }^{\circ} \mathrm{C}$ and $90 \% \mathrm{RH}$ is shortened by 2,4-DP applications compared to nontreated-fruit (Kondo and Takano, 2000), the two applications at 140 and 150 DAFB were more effective (Fig. 3). However, all 2,4-DP applications shortened the period until edibility firmness at $20^{\circ} \mathrm{C}$ and $90 \%$ RH compared to nontreated fruit. Even when ethylene production is slowed by low temperatures, and fruit ripens late on the tree, 2,4-DP application is assumed to promote postharvest ripening.

The potential ethylene production differs among cultivars. Generally the concentration is high in early cultivars but low in late-cultivars (Kondo et al., 1991). Thus, the induction of ripening by 2,4-DP applications may be effec-

Table 1. Polyuronide, hemicellulose, and cellulose concentrations ( $\mathrm{mg} \cdot \mathrm{g}^{-1}$ fresh weight) in cell wall fractions of pears. Data are the means of three replications

\begin{tabular}{|c|c|c|c|c|c|c|c|c|c|c|c|c|c|c|c|c|c|c|c|c|}
\hline \multirow[b]{2}{*}{ DAFB } & \multicolumn{4}{|c|}{ Nontreated } & \multicolumn{4}{|c|}{ Early 1} & \multicolumn{4}{|c|}{ Early 2} & \multicolumn{4}{|c|}{ Late 1} & \multicolumn{4}{|c|}{ Late 2} \\
\hline & WSP & HMP & HCE & $\mathrm{CE}$ & WSP & HMP & $\mathrm{HCE}$ & $\mathrm{CE}$ & WSP & HMP & $\mathrm{HCE}$ & $\mathrm{CE}$ & WSP & HMP & $\mathrm{HCE}$ & $\mathrm{CE}$ & WSP & HMP & $\mathrm{HCE}$ & $\mathrm{CE}$ \\
\hline$\overline{170}$ & 0.29 & 5.65 & 1.49 & 10.12 & 0.56 & 4.28 & 1.10 & 5.04 & 0.57 & 5.61 & 1.17 & 5.22 & 0.50 & 5.63 & 1.32 & 7.95 & 0.52 & 5.61 & 1.43 & 8.58 \\
\hline 180 & 0.31 & 4.22 & 1.45 & 9.85 & 0.63 & 3.68 & 0.75 & 4.72 & 0.92 & 3.98 & 0.78 & 4.85 & 0.55 & 4.19 & 1.17 & 6.40 & 0.57 & 4.22 & 1.35 & 7.94 \\
\hline 190 & 0.80 & 3.84 & 1.14 & 8.53 & 1.34 & 2.30 & 0.73 & 3.44 & 1.63 & 1.41 & 0.73 & 3.77 & 1.14 & 2.10 & 0.73 & 6.78 & 1.36 & 2.67 & 0.77 & 7.51 \\
\hline 200 & 0.92 & 3.23 & 0.86 & 6.98 & 2.00 & 1.87 & 0.61 & 2.84 & 2.12 & 1.32 & 0.61 & 2.62 & 1.20 & 1.78 & 0.73 & 4.03 & 1.46 & 1.91 & 0.66 & 4.80 \\
\hline 207 & 1.42 & 2.04 & 0.76 & 5.41 & 2.19 & 1.26 & 0.63 & 2.98 & 2.33 & 1.19 & 0.72 & 2.83 & 1.61 & 1.34 & 0.69 & 3.63 & 1.89 & 1.23 & 0.58 & 3.31 \\
\hline \multicolumn{21}{|c|}{$\mathrm{LSD}_{0.05} \mathrm{WSP}=0.08, \mathrm{HMP}=0.31, \mathrm{HCE}=0.05, \mathrm{CE}=0.48$} \\
\hline
\end{tabular}

WSP: water-soluble polyuronide, HMP: hexametaphosphate-soluble polyuronide, HCE: hemicellulose, CE: cellulose. See Fig. 1 for explanation of treatments. 


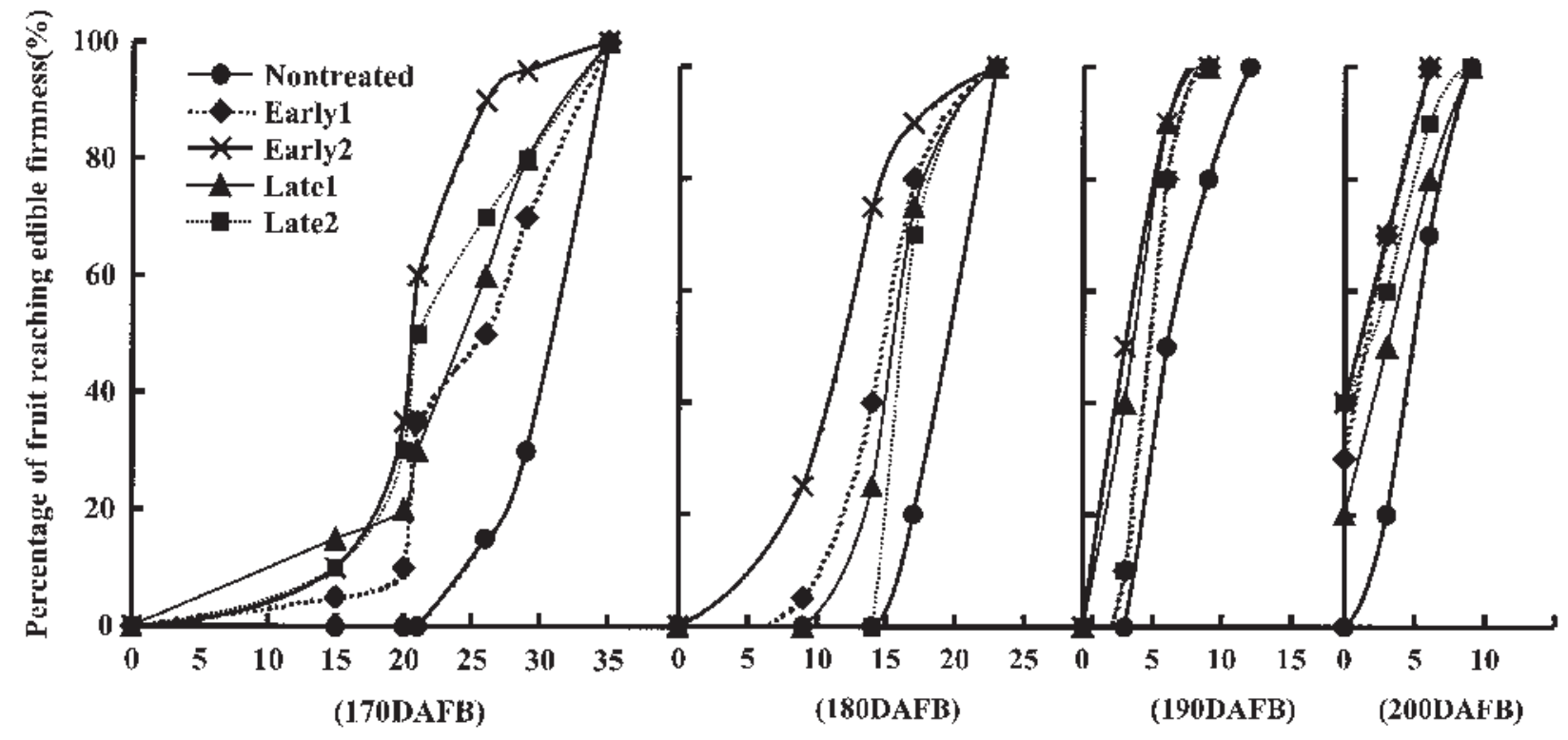

Days stored at 20 "C and 90\% RH

Fig. 3. Days kept to reach edible firmness $(<0.3 \mathrm{~N} / \mathrm{mm})$ at $20^{\circ} \mathrm{C}$ and $90 \%$ relative humidity $(\mathrm{RH})$ after each harvest date $[170,180,190$, and $200 \mathrm{~d}$ after full bloom (DAFB)] of Early 1, Early 2, Late 1, and Late 2 and Nontreated. See Fig. 1 for legend details. Twenty fruit were used in each treatment.

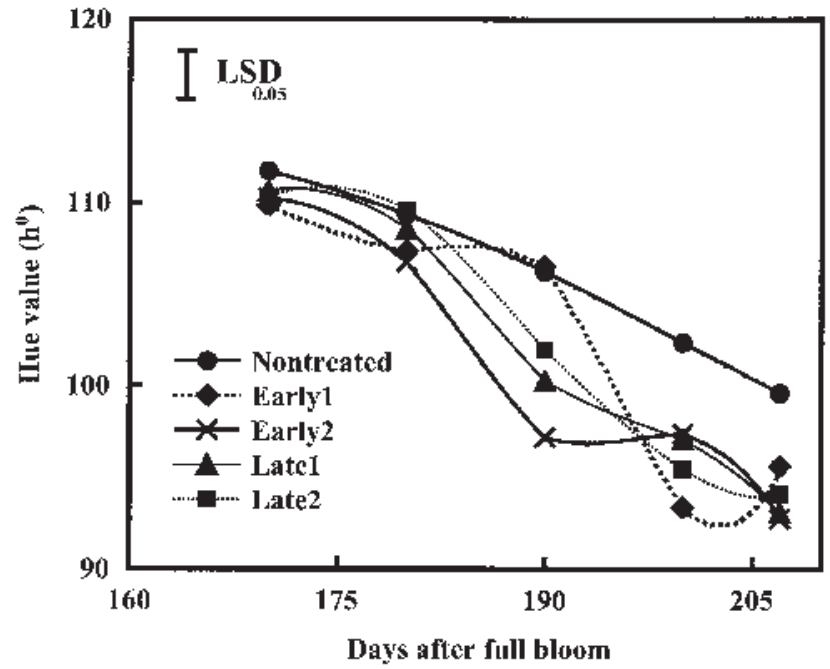

Fig. 4. Ground color shown by hue value of pears on the tree. Hue values are expressed as follows: $0^{\circ}=$ red-purple, $90^{\circ}=$ yellow, $180^{\circ}=$ bluish-green $270^{\circ}=$ blue. Data are the means of 10 fruit.

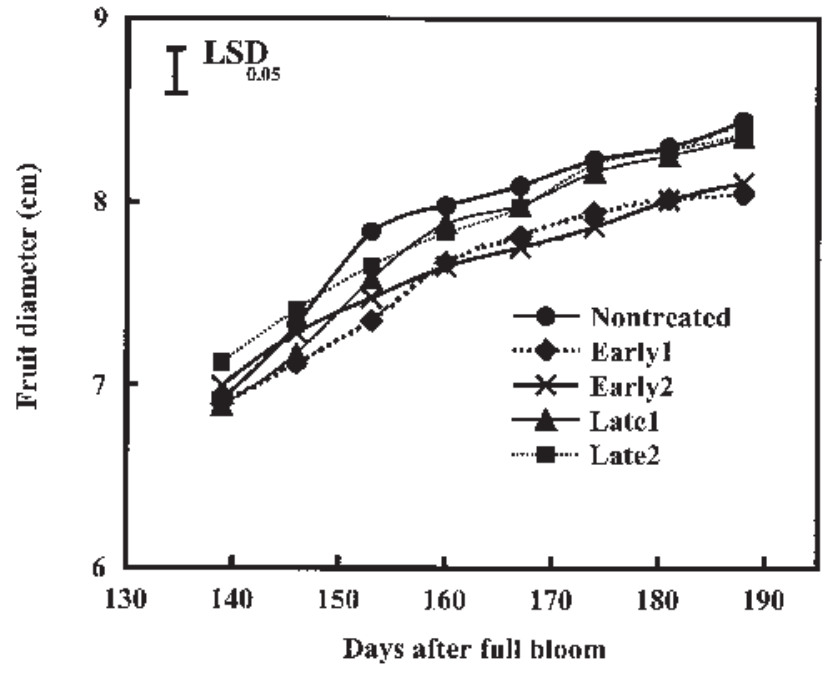

Fig. 5. Fruit growth after 2,4-DP applications. Data are the means of 15 fruit. tive in the cultivars that have potentially high ethylene production and also have high ambient temperatures after 2,4-DP applications. A larger scale experiment should be undertaken in areas that have different climates.

Fruit growth was reduced after 2,4-DP application because development shifted to ripening (Fig. 5). Therefore, applying 2,4-DP too early may cause inferior marketability.

\section{Literature Cited}

Abu-Sarra, A.F. and A.A. Abu-Goukh. 1992 Changes in pectinesterase, polygalacturonase and cellulase activity during mango fruit ripening. J. Hort. Sci. 67:561-568.
Blankenship, S.M. and D.G. Richardson. 1985. Development of ethylene biosynthesis and ethylene-induced ripening in 'd'Anjou' pears during the cold requirement for ripening. J. Amer. Soc. Hort. Sci. 110:520-523.

Ferguson, I.B. 1984. Calcium in plant senescence and fruit ripening. Plant Cell Environ. 7: 477-489.

Gerasopoulos, D. and D.G. Richardson. 1997. Storage-temperature dependent time separation of softening and chlorophyll loss from the autocatalitic ethylene pathway and other ripening events of 'Anjou' pears. J. Amer. Soc. Hort. Sci. 122:680-685.

Kondo, S. and Y. Hayata. 1995. Effects of AVG and 2,4-DP on preharvest drop and fruit qual- ity of 'Tsugaru' apples. J. Jpn. Soc. Hort. Sci. 64:275-281.

Kondo, S. and Y. Takano. 2000. Cell wall metabolism and induction of ripening capacity in ' $\mathrm{La}$ France' pear as influenced by 2,4-DP. J. Amer. Soc. Hort. Sci. 125:242-247.

Kondo, S., J. Uthaibutra, and H. Gemma. 1991. Comparison of 1-aminocyclopropane-1-carboxylic acid, abscisic acid and anthocyanin content of some apple cultivars during fruit growth and maturation. J. Jpn. Soc. Hort. Sci. 60:505-511.

Lau, O.L., Y. Liu, and S.F. Yang. 1986. Effects of fruit detachment on ethylene biosynthesis and loss of flesh firmness, skin color, and starch in ripening 'Golden Delicious' apples. J. Amer. Soc. Hort. Sci. 111:731-734. 


\section{Growth Regulators}

Manabe, T. 1993. Comparative examination of the three quantitative methods of pectin (carbazole, m-hydroxydiphenyl and 3, 5-dimethylphenol method). Hiroshima Pref. Univ. Bul. 5:141-150.

McCollum, T.G., D.J. Huber, and D.J. Cantliffe. 1989. Modification of polyuronides and hemicelluloses during muskmelon fruit softening. Physiol. Plant. 76:303-308.

Mizuno, T. and Y. Iwata. 1964. Application of the phenol-sulfuric acid method for fractional determination of polysaccharides. J. Jpn. Soc.
Food Sci. Technol. 11:395-399.

Murayama, H., T. Takahashi, R. Honda, and T. Fukushima. 1998. Cell wall changes in pear fruit softening on and off the tree. Postharvest Biol. Technol. 14:143-149.

Murayama, H., T. Katsumata, O. Horiuchi, and T. Fukushima. 2002. Relationship between fruit softening and cell wall polysaccharides in pears after different storage periods. Postharvest Biol. Technol. 26:15-21.

Peck, S. and H. Kende. 1995. Sequential induction of the ethylene biosynthetic enzymes by indole-
3 -acetic acid in etiolated peas. Plant Mol. Biol. 28:293-301.

Saltveit, M.E. 1992. Regulation of ethylene production by nonstress external factors, p. 56-119. In: F.B. Abeles, P.W. Morgan, and M.E. Saltveit, Jr. (eds.). Ethylene in plant biology. Academic, New York.

Yoshioka, H., K. Aoba, and Y. Kashimura. 1992. Molecular weight and degree of methoxylation in cell wall polyuronide during softening in pear and apple fruit. J. Amer. Soc. Hort. Sci. 117: 600-606. 